\title{
Os processos de RVCC na educação de adultos: evolução ou involução metodológica?
}

\author{
Anabela Rodrigues de Abreu Morais \& Albertina L. Oliveira \\ Faculdade de Psicologia e Ciências da Educação da Universidade de Coimbra
}

\begin{abstract}
Resumo
O processo de Reconhecimento, Validação e Certificação de Competências (RVCC) escolares e profissionais conjuga atualmente, de forma contraditória, metodologias baseadas na história de vida do sujeito e outras próprias da educação formal escolarizante como a inclusão de uma prova escolar e/ou profissional no final do processo. Para aferir o impacto destas "novas orientações metodológicas', considerámos pertinente realizar um estudo pioneiro junto de adultos que realizaram os referidos processos para conhecer a sua perspetiva acerca do novo formato. Foram entrevistadas 5 participantes, através de questões abertas, apontando os primeiros resultados para opiniões diferenciadas em vários aspectos, e uma maior consistência noutros.
\end{abstract}

A discussão em torno do que é, por definição, um adulto e a necessidade de adaptar as metodologias às necessidades específicas de um indivíduo, com uma história de vida longa e variada, levaram organismos, como a UNESCO, através das Conferências Internacionais de Educação de Adultos, do "Relatório Delors", e a Comissão Europeia, através da Estratégia Europeia para o Emprego em 2001, a chamar a atenção para a forma como o adulto aprende, ao longo da vida, alertando para a especificidade da sua forma de aprender, construindo e reconstruindo o seu conhecimento e a sua realidade em interação consigo próprio e com os outros em múltiplos contextos.

Esta perspetiva holística e contextualizada da Educação de Adultos entende que a perspetiva tradicional de que o adulto é uma "tábua rasa" que aprende passivamente através da exposição e transmissão de conhecimentos pelo professor, que devem ser apenas avaliados pontualmente por um exame padrão que não considera a particularidade da realidade de cada sujeito, não serve as reais necessidades formativas do adulto e leva a uma generalização dos resultados em classificações rotulantes que avaliam o todo por uma parte e que devido à sua natureza restritiva, não é a forma mais adequada de avaliar os conhecimentos dos adultos.

Segundo Dominicé (2002), uma perspetiva baseada nas histórias de vida, aplicada ao campo da educação e formação de adultos é "o único método de investigação pertinente, uma vez que oferece um acesso direto ao conhecimento construído pelos próprios adultos, bem como aos seus modos quotidianos de formalização" do saber. Os relatos autobiográficos são mais do que um exercício de memória retrospetiva e de reflexão crítica. As histórias de vida são "uma metodologia de investigação e de construção de sentido a partir de factos temporais passados" (Pineau \& Le Grand, 1996). Neste sentido, as histórias de vida devem ser o início de uma transformação profunda da forma como o adulto se vê e é visto pelos pares e pela sociedade. O adulto deve ser o catalisador da ação para reconstruir a realidade em que vive e assumir-se como um ser autónomo, responsável pelo seu destino individual e coletivo.

Em Portugal, com o objetivo de relançar uma política de Educação de Adultos de vanguarda que chegasse a uma grande parte da população com baixa escolaridade foram criados os Centros de Reconhecimento, Validação e Certificação de Competências (CRVCC, pela anterior Agência, ANEFA), aos quais de sucederam os Centros Novas Oportunidades (CNOs), através da Portaria n. ${ }^{\circ} 370 / 2008$ de 21 de maio com o objetivo de elevar a escolaridade e a qualificação profissional dos adultos através do reconhecimento validação e certificação de competências escolares e profissionais adquiridas através da experiência de vida, particularmente em contextos informais e não formais.

Os destinatários eram os adultos que tinham mais de 18 anos e que já possuíam competências e saberes, fruto das suas experiências de vida e de trabalho e que pretendiam vê-las reconhecidas formalmente.

Através desta metodologia, o adulto deveria (sob orientação da equipa técnica dos CRVCC e CNOs constituída por técnicos e formadores) construir um portefólio reflexivo de aprendizagens que deveria orientar-se segundo um referencial de competências chave. Assim, a avaliação do processo de RVCC era feita exclusivamente através da análise do portefólio do adulto e de uma pequena apresentação preparada pelo mesmo sobre o trabalho desenvolvido perante um júri de certificação constituído pela equipa que acompanhou o adulto ao longo do processo e por um avaliador externo. Destas duas condições resultaria uma certificação total ou parcial das competências e saberes do adulto.

Contudo, e apesar de se terem obtido resultados significativos (cerca de 400 mil certificações) no aumento da qualificação da população através deste método de reconhecimento de saberes adquiridos, a Iniciativa Novas Oportunidades que sustentava politicamente os CNO é extinta em 2013. No mesmo ano são criados os seus sucedâneos - os Centros para a Qualificação e Ensino Profissional (CQEPs) através da publicação da Portaria n. ${ }^{\circ} 135-\mathrm{A} / 2013$ de 28 de março. Estes Centros adquirem valências e âmbitos de ação 
mais abrangentes, permanecendo habilitados para a certificação escolar e profissional do adulto através de processos de reconhecimento, validação e certificação de competências.

Uma das principais novidades incluída no processo, com o argumento de que o tornaria mais credível e fidedigno, foi a introdução de uma prova que o adulto tem de realizar, no final do processo de RVCC, perante um júri de certificação, totalmente externo ao processo, com vista a quantificar as suas reais capacidades, conhecimentos e competências em comparação com aquelas que demonstrou ao longo da construção do portefólio.

Este novo modelo avaliativo dos processos de RVCC que culmina numa prova de demonstração de competências (inexistente na versão anterior) traz uma perspetiva inédita sobre como avaliar conhecimentos e competências que, pela sua natureza não são, à partida, mensuráveis pelos padrões normais, devido ao grau de subjetividade que tal implica, e estabelece uma aparente contradição com a forma como a Educação e Formação de Adultos surgiu na sua génese. Martins (2013) afirma mesmo que "não é possível atribuir um valor quantitativo a um processo (...) em que a centralidade do próprio no reconhecimento e na produção da competência é central” (p. 316). No seguimento deste raciocínio Martins (2003) acrescenta que a "introdução de classificações quantitativas num dispositivo que pretende que sejam os próprios a reconhecer e desocultar as suas competências" (p. 317) é contraproducente pois "levanta sérios problemas técnicos e epistemológicos do ponto de vista da avaliação de competências" (p. 327).

Assim sendo, na tentativa de contribuir para esclarecer algumas das questões colocadas anteriormente, e devido ao fato do processo de RVCC, praticado nos CQEP's se apresentar numa fase muito inicial de implementação, não havendo ainda produção científica que evidencie a sua adequação, elegemos esta problemática como tema de investigação.

Pretendemos, assim, com esta investigação aceder e identificar as perceções que os adultos têm acerca do novo processo RVCC, particularmente em relação à introdução de uma prova de demonstração de competências no processo de RVCC.

\section{Participantes}

\section{Método}

Definimos como grupo de participantes, nesta investigação, cinco adultos, empregados, que exercem a sua profissão em instituições que desenvolvem atividade profissional na área de Trabalho Social e Orientação segundo o Catálogo Nacional de Qualificações (CNQ), tendo como público-alvo os idosos.

Estes adultos, todos do sexo feminino e de idades compreendidas entre 31 e 53 anos, concluíram o processo de RVCC segundo as novas diretrizes impostas pelo novo modelo dos CQEP, com realização de prova de demonstração de competências no final do processo.

\section{Instrumentos}

A metodologia de investigação escolhida é de cariz qualitativo, com o recurso a entrevistas semidiretivas. O motivo desta escolha prende-se com o objetivo da investigação ser a compreensão das perceções e significados que o grupo de participantes tem acerca do processo de RVCC em geral, e da prova, em particular, quando aplicada num determinado contexto ou situação (neste caso num processo de RVCC) e de que forma este fator faz sentido para os sujeitos investigados, como interfere nos seus comportamentos, atitudes e opções.

Por ser esta uma investigação que só adquire significado em contexto e não pode ser, à partida, generalizado, por dizer respeito a investigação de um universo muito próprio dos adultos, dependente das suas próprias representações da realidade, das suas emoções, sentimentos e percursos individuais, uma metodologia totalmente estruturada com atributos de rigidez e normatividade, como é a investigação quantitativa, não faria sentido nesta situação.

Foi também utilizada a análise documental para apurar dados mais específicos acerca dos adultos como, por exemplo, idade, percurso escolar/formativo e experiência profissional.

\section{Procedimentos}

Dentro do grupo de participantes nem todos fizeram um processo nos mesmos moldes: duas das adultas entrevistadas concluíram o processo de RVCC, de dupla certificação, com vista à obtenção do nível básico de qualificação escolar e do nível 2 de qualificação profissional na saída profissional de Agente em Geriatria. As restantes três adultas obtiveram a qualificação profissional de nível 2 , de Agente em Geriatria, fazendo um processo de RVC Profissional (RVCPro);

Para a realização das entrevistas foi necessário pedir autorização formal aos responsáveis das instituições escolhidas para a investigação, através da assinatura, por ambas as partes, de um termo de consentimento informado. O mesmo procedimento foi realizado com cada uma das participantes a quem foram explicados os objetivos da investigação e os moldes em que a entrevista iria decorrer. Após serem assegurados os pressupostos éticos da confidencialidade dos dados e a sua utilização exclusiva para esta investigação foi assinado o respetivo termo de consentimento informado pelas partes envolvidas.

Após a realização das entrevistas e respetiva transcrição foi efetuada a análise de conteúdo cujos resultados se apresentam de seguida.

\section{Resultados}

Em relação ao conhecimento prévio acerca da forma como os processos são agora conduzidos, as opiniões divergem. Se, por exemplo, P8 já conhecia as características principais deste processo por ter feito um processo de nível básico nos antigos CNOs, $\mathrm{P} 8$, por outro lado, desconhecia as alterações efetuadas assim como a criação dos CQEPs: "só fiquei a saber no 
momento em que entrei no processo (...) desconhecia completamente." Estas declarações denunciam ainda um conhecimento insuficiente ou mesmo nulo das principais diferenças que distinguem o antigo processo do que agora entrou em vigor, denotando que existe ainda um défice na divulgação desta modalidade de certificação, que não está a chegar de forma eficaz ao seu público-alvo, devendo ocorrer um esforço redobrado na divulgação e promoção deste tipo de modalidade.

Podemos dizer, pelos testemunhos recolhidos que as razões para iniciar um processo de RVCC são inúmeras. As respostas centram-se, principalmente, no fato de cada uma das entrevistadas considerar estes processos como uma mais-valia para a sua formação e certificação escolar/profissional como é o caso de P1, P2 e P5. Estes processos são vistos como uma boa forma de aumentar a escolaridade como refere $\mathrm{P} 1$ ao afirmar: "agora achei por bem fazer o $9^{\circ}$ ano". Por sua vez, P8 encara este processo como uma forma de valorização pessoal. Para as participantes P5 e P8, e o principal motivo que as levou a iniciar o processo de RVCC foi obter valorização profissional como afirmam P2 e P5, ou simplesmente e também fomentar o gosto por aprender

$\mathrm{O}$ processo de reconhecimento, validação e certificação de competências inicia-se, atualmente, por um conjunto de etapas que antecedem o início efetivo do processo e que se denominam de Orientação ao Longo da Vida (OLV). Esta etapa é constituída por uma fase de acolhimento na qual é feita a apresentação das etapas do processo, dos seus objetivos, e dos referenciais de competências chave que irão orientar a construção do portefólio na etapa seguinte.

Apesar de no início o novo modelo suscitar algumas dúvidas, principalmente na interpretação do referencial, após a explicação adicional por parte da equipa técnica, todas as entrevistadas perceberam em que consistia o processo, os seus objetivos e quais as tarefas a realizar, estabelecendo, facilmente, um paralelismo entre as tarefas que executam no dia-a-dia e as competências que constam no respetivo referencial.

A etapa seguinte do processo denomina-se de fase de reconhecimento de competências e é constituída por vários instrumentos de regulação, aperfeiçoamento e reforço da perceção das reais capacidades dos adultos em relação ao referencial visado. Esta fase é constituída pela construção do portefólio, por uma entrevista técnica conduzida por um formador na área, por exercícios práticos ou observação em posto de trabalho (quando aplicável) e por um momento de formação que pode ser de teor prático ou teórico, em sala de aula.

Relativamente a esta fase, todas as entrevistadas salientam que o sucesso obtido na construção do portefólio só foi possível graças ao acompanhamento e orientação constantes da equipa técnica salientando que "ao longo das sessões (...) fui construindo esse conhecimento" P5 e "com a colaboração de todos e nomeadamente dos que nos davam a formação foi-se fazendo o trabalho (...); os professores foram excelentes" conclui P1.
Todas as participantes concordam que apesar de algumas dificuldades iniciais para entender a "linguagem específica e técnica" dos referenciais, esta atividade de construção de um portefólio foi fácil de realizar. Já a entrevista técnica, orientada por um formador da área de especialização a certificar, é tida como um dos fatores que mais contribui para a melhoria do portefólio após a primeira avaliação deste, pois, como diz P2:" Fiquei com dúvidas nessa parte (...) mas depois (...) mais fácil.”

A etapa seguinte do processo implica a execução de alguns exercícios práticos perante a formadora especializada na área de certificação e que, segundo as adultas referem, "faz sentido neste processo. "As pessoas têm... nós temos que ser avaliados por aquilo que sabemos não é?" questiona P5. Por seu lado, P12 sublinha que "devíamos ter feito mais! (...) temos que demonstrar que realmente temos conhecimento (...) Ajuda ser avaliada por um bom avaliador!". Em suma, a entrevista técnica é uma etapa essencial para esclarecer dúvidas que não tenham ficado claramente esclarecidas em etapas anteriores, funcionando como um reforço e clarificação do que "nós costumamos fazer no dia-a-dia no nosso trabalho" (P1), ou como forma de correção de "vícios de trabalho", pois como menciona P2 "tivemos que corrigir durante o tempo que esteve connosco e nos esteve a ensinar a corrigir algumas coisas".

Outro dos objetivos desta entrevista técnica, seguida de exercícios práticos, é a identificação de necessidades de formação do adulto em processo de RVCC. Esta formação destina-se àqueles que, em uma ou mais áreas de competências revelam inconsistência de conhecimentos que exigem um acompanhamento mais estruturado e direcionado para o cumprimento das tarefas do portefólio. Neste caso, está previsto um período de formação que pode ir até ao máximo de $50 \mathrm{~h}$, para melhorar competências profissionais e de outras 50h no caso de se estar a realizar uma certificação escolar. Estas 50h, no caso de certificação escolar devem ser distribuídas, pelas várias áreas de competências chave constantes do referencial de competências chave de nível básico ou secundário, consoante os casos.

As participantes são unânimes ao afirmar que a inclusão de um momento de formação no processo de RVCC, para aprimorar conhecimentos, é uma maisvalia indiscutível que lhes permite melhorar alguns aspetos do portefólio que não foram totalmente concretizados na fase inicial. P1 por exemplo assegura que a formação "foi muito útil". Por seu lado, P8 sublinha que a formação é importante pois "veio reavivar e tudo muito bem. (...) se não fazemos temos de aprender". No entanto, quando questionadas acerca da duração da formação (máx. $50 \mathrm{hrs}$ ) as opiniões divergem. Se, por seu lado, P1 defende que "foi o suficiente sim", as restantes participantes não têm dúvidas de que "foram poucas (horas) havia de ter sido mais (...) talvez ser outras 50h para ficar mesmo". Como afirma P12, uma formação de 50h “é pouco! É pouco muito pouco...(...)50h é um mês, passa a correr!". Assim, podemos concluir que em relação à 
duração da formação as perceções das entrevistadas são maioritariamente de que são insuficientes e que a formação, apesar de ter sido uma mais-valia indubitável para o processo, deveria ser uma parte substancial deste para reforçar conhecimentos já adquiridos, mas principalmente para a aquisição de novos comportamentos e boas práticas na sua atividade profissional, e para melhorar o portefólio e assim ter maior probabilidade de validar competências que resultem numa certificação total.

Após esta fase de reconhecimento de competências, as adultas passam à sessão de validação que estipula claramente, após análise dos diferentes instrumentos de avaliação utilizados no processo de reconhecimento, o que cada adulto está preparado para demonstrar na prova que se fará na fase seguinte de certificação de competências.

No que concerne à etapa de certificação de competências e à realização de uma prova final a opinião das participantes é positiva sublinhando que esta prova foi ao encontro das expetativas dos adultos, sendo bem compreendida por estes em termos de objetivos e tarefas a desenvolver, como referiu P1 "percebia-se bem (...) foi fácil" e P2 "eu compreendi (...) fácil de entender". Em relação à existência de variedade de tipos de prova (prática, oral, escrita ou mista) todas as participantes afirmam, sem sombra de dúvida que, "é bom sim. Se fosse só oral (...) eu atrapalho - me um bocadinho muitas vezes a falar" confessa P1. P2 partilha desta opinião dizendo que "foi bem assim (...) escrevemos, não sabemos se está muito bem ou se está mal. Na parte oral é bom porque vamos falando (...) se calhar até dizemos mais do que pomos no papel ou explicamos melhor do que aquilo que pomos no papel"

Quanto à utilidade da prova num processo que tem como principal objetivo certificar competências demonstradas, todas as participantes reconhecem a utilidade de uma prova formal de demonstração de conhecimentos como indica $\mathrm{P} 1$ “ A prova é muito útil eu acho que é bom...(...) nós andarmos la a tentar fazer pronto o $9^{\circ}$ ano ou a escolaridade e depois também no final não termos uma prova? na escola também temos as provas nos finais do ano (...). Reforçando esta convicção temos P5 que afirma "nós temos que ser avaliados por aquilo que sabemos". Contudo existem opiniões dissonantes. P2 deixa um desabafo ao afirmar que "eu acho é que é pena não ser feita por quem nos dá as aulas, estaríamos mais à vontade". Contudo, o recurso a um júri externo a todo o processo tem como finalidade garantir a idoneidade e imparcialidade dos resultados que se acredita estarem assegurados caso o júri fosse constituído pelos formadores afetos ao processo.

Quando inquiridas acerca do peso que a prova tem na classificação final do processo $(60 \%)$, em comparação com todo o processo de reconhecimento de competências, que corresponde apenas a $40 \%$ da nota final, as opiniões dividem-se. P1, P2 e P12 concordam que a prova deve pesar mais pois é uma prova irrefutável de que o adulto sabe ou não sabe executar as tarefas inerentes à sua atividade profissional de forma exemplar, de acordo com as boas práticas da profissão. As restantes participantes (P5 e P8) concordam com uma distribuição equitativa de classificação na ordem dos 50/50 por etapa.

Apesar das participantes concordarem com a realização de uma prova de demonstração de competências para quantificar as competências adquiridas através da experiência de vida, P12 salienta que "eu sei mais do que aquilo... com certeza" recordando que por mais completa que seja a prova esta terá sempre uma ação e um impacto limitados naquilo que o adulto realmente sabe, visto que os conhecimentos adquiridos são tão variados e vastos que seriam impossíveis de avaliar numa única prova no tempo estabelecido.

Em geral todas as participantes ficaram satisfeitas com a nota obtida na prova, afirmando que graças a este processo alteraram a perceção que têm de si, reforçando sentimentos positivos como realização pessoal e autoestima e autoconfiança que transpõem para a sua atividade profissional, esforçando-se hoje por aplicar os conhecimentos adquiridos como afirma P2 "tento sempre mudar e fazer mais corretamente". Este processo promoveu também alterações ao nível dos hábitos e formas de ocupação dos tempos livres destas adultas. Por exemplo, P1 e P2 afirmam que, hoje, graças a este processo readquiriram o gosto pela escrita e pela leitura assim como pelas novas tecnologias "todos os bocados que posso leio livros (...) o computador já ganhei o "bichinho" já tenho ido mais vezes ao computador. Também ao nível social se registaram alterações que se traduzem numa maior facilidade em utilizar dispositivos eletrónicos como o computador ou o telemóvel, testemunhadas por P1, ou a evolução significativa das competências sociais de P2 quando esta afirma que fazer este processo "põem nos à vontade para falarmos mais abertamente com outras pessoas".

\section{Discussão}

Perante os resultados obtidos podemos afirmar que a perceção dos adultos em relação aos processos de reconhecimento, validação e certificação de competências é positiva.

Todos os participantes concordam que este processo é uma excelente forma de obter uma qualificação profissional através da certificação de competências adquiridas pela experiência de vida que, desta forma, são reconhecidas e valorizadas.

Contudo, ao longo das entrevistas foram também detetadas algumas observações críticas, como a maioria das adultas ter referido que a duração da formação foi insuficiente para adquirir conhecimentos. No entanto, temos que ver estas afirmações à luz do que é entendido como formação em contexto de RVCC. Nestes processos a formação tem como principal objetivo o aperfeiçoamento de técnicas e não propriamente a aquisição de conhecimentos novos ou competências que não tenham sido, de todo, comprovadas através das estratégias de avaliação utilizadas anteriormente. Podemos pois concluir que os 
adultos ainda associam os processos de RVCC a uma ação de formação convencional na qual aprendem novos conceitos e técnicas que são depois avaliadas por uma prova, à semelhança do que sucede num curso de formação convencional ou na escola regular.

Esta visão tradicional dos processos manifesta-se desde logo na forma como as adultas falam desta metodologia referindo-se aos mesmos como "formação" e que se reflete nas motivações e razões que as levaram a aderir facilmente a estes processo, ao declararem, por exemplo, que o que pretendem é "aprender mais "e que fizeram o processo por "gostar de aprender".

Esta questão leva-nos a crer que as participantes possuem ainda uma visão deste processo decalcada do modelo escolar Mesmo quando este implica que, através da descodificação dos referenciais, os adultos façam uma retrospetiva crítica acerca do que aprenderam ao longo da vida, colocando-se no centro da ação de forma ativa e autónoma. Um processo pessoal, imanentemente reflexivo e autónomo que o adulto deve realizar acerca das suas aprendizagens experienciais confunde-se com um processo de aquisição de conhecimentos provenientes de elementos externos como, por exemplo, através de um formador que, utilizando uma abordagem diretiva e estruturada, pretende que o aluno chegue a um resultado satisfatório segundo uma escala padronizada.

Consequentemente, do ponto de vista das adultas entrevistadas, apesar de saberem o essencial, este processo "ensinou-as" a fazer melhor o seu trabalho e não tanto a refletir acerca do seu percurso de vida. Neste contexto, a certificação é um bónus acrescido. Assim, o processo ao qual estiveram sujeitas contribuiu, significativamente, para a visão que as adultas têm do processo, não tanto como um processo reflexivo, tal como metodológica e concetualmente foi arquitetado, mas de cariz formativo e certificativo. Esta perspetiva levou as adultas a encarar de forma mais natural o facto de, no fim do processo, terem de ser avaliadas por um júri através da realização de uma prova. Segundo elas, só assim se pode comprovar o que sabem mas, sobretudo, o que aprenderam.

Em suma, estes processos são vistos pelos adultos como uma boa forma de valorização pessoal e de certificação de competências, pois como disse P12 "É uma certificação que eu sei fazer aquilo", que a introdução de uma prova final vem apenas reforçar e legitimar, dando um novo sentido a uma metodologia de reconhecimento de conhecimentos adquiridos (P5, P8 e P12) que deve ser valorizado e instituir-se como uma alternativa clara de qualificação para quem não pôde estudar no tempo devido (P2) ou como meio para melhorar e aprimorar aquilo que já se sabe (P1, P2 e $\mathrm{P} 12)$, sendo, por isso, uma metodologia altamente recomendada por todas as adultas participantes na investigação.

Relativamente às limitações/ constrangimento desta investigação importa sublinhar que estas conclusões basearam-se em resultados obtidos a partir de cinco depoimentos de adultas que fizeram certificação escolar de nível básico (em dois casos) e numa certificação numa única saída profissional (Agente em Geriatria). Porém é nossa intenção alargar o número de participantes a um total de vinte adultas que irão obter, a curto prazo, uma certificação nas modalidades acima referidas mas também nas saídas profissionais de Acompanhante de Crianças e de Técnica de Ação Educativa (nível 2 e nível 4 do CNQ, respetivamente). Assim, a investigação irá prosseguir com a obtenção de mais dados provenientes de outros participantes a frequentar processos no âmbito de outras áreas profissionais.

Outra das limitações/constrangimentos desta investigação é a impossibilidade de generalizar os resultados devido a serem referentes apenas ao CQEP do Centro de Formação Profissional do Artesanato (CEARTE).

Contudo, consideramos que o fato de estes dados corresponderem a uma investigação pioneira no âmbito dos processos de RVCC, segundo as novas diretrizes que regem esta modalidade de certificação, abre caminho para uma análise mais direcionada e fundamentada acerca do impacto que estes processos têm na vida dos adultos e na forma como estes se reveem nesta realidade, à luz dos princípios da Educação e Formação de Adultos de hoje, podendo servir como referência para estudos futuros.

A posteriori consideramos importante realizar investigações que abranjam não só adultos que tenham obtido certificação escolar de nível básico mas também de nível secundário, assim como noutras áreas profissionais que possibilitem uma compreensão mais aprofundada dos dados que começam a emergir.

Neste âmbito, sugerimos também que em futuras investigações se auscultem as perceções dos Técnicos de Orientação, Reconhecimento, Validação e Certificação (TORVC) e dos formadores acerca destes novos processos. Qual a importância da obtenção de um diploma através do novo processo de RVCC para a procura de emprego e progressão na carreira do adulto? Qual a real importância deste processo no contexto mais alargado da vida do/a adulto/a?

\section{Referências}

Delors, J., e al. (1996). Educação um tesouro a descobrir. Relatório para a UNESCO da Comissão Internacional sobre Educação para o Século XXI. http://ftp.infoeuropa.eurocid.pt/database/000046 001-000047000/000046258.pdf

Dominicé, P., (1992). L'históire de vie comme processos de formation. Paris: L'Harmattan.

Martins, J. E. R., (2014). Das políticas às práticas de educação de adultos. Lógicas de ação, sentidos e modos de apropriação localmente produzidos. Tese de Doutoramento, Faculdade de Ciências Sociais e Humanas, Universidade Nova de Lisboa, Lisboa, Portugal. http://hdl.handle.net/10362/11395

Pineau, G., \& LeGrand, J. L. (1996). Histoires de vie. Paris: Presses Universitaires de France.

Portaria n. ${ }^{\circ}$ 370/2008. (2008). Criação dos Centros Novas Oportunidades. Diário da República: I série. N. ${ }^{o} 98$ (08-05-28), 2898-2906. 
RODRIGUES E OLIVEIRA

Portaria n. ${ }^{\circ}$ 370/2008. (2008). Criação dos Centros Novas Oportunidades. Diário da República: I série.

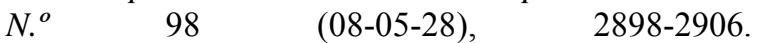

Portaria n. ${ }^{\circ} 135-A / 2013$, (2008). Criação dos Centros para a Qualificação e o Ensino Profissional. Diário da República: I série. N. ${ }^{\circ} 62$ (13-03-28), 1914-(2)1914-(10). 